\title{
Hypersensitivity to Antigen Derived from Brain Tissue in Patients with Huntington's Disease and in Individuals at Risk
}

Ronald S. Walls and Anita Ruwoldt

Immunology Unit, Department of Medicine, University of Sydney, Concord Hospital, Concord, New South Wales, Australia

bstract. The hypothesis that an immune response is directed to components of brain tissue in Huntington's disease (HD) was examined. 27 patients with HD, 21 children of affected parents who showed no signs of disease, 6 spouses of HD patients, and 40 patients with other neurologic diseases were investigated. Leukocyte migration inhibition to antigens prepared from brain tissue was demonstrated in $26 \mathrm{HD}$ patients and in 9 children. None of the six spouses reacted. 13 patients with other neurologic conditions (including $60 \%$ of patients after cerebrovascular accidents) reacted to rat brain extract. Fractionation of brain tissue indicated that the material responsible for reactions in these patients differed from that in HD. The material that elicited hypersensitivity in HD was not species specific, since it was found in rat, calf, human, and rabbit brain. It was not present in rat kidney, liver, or heart. Preliminary characterization showed that the material was protein in nature, contained sugar and lipid, and was heat labile. The finding of hypersensitivity in about half the unaffected children of HD parents suggests that it may precede the clinical onset of disease and serve as a marker for the gene.

\section{Introduction}

Huntington's disease (HD) ${ }^{1}$ is an autosomal, dominantly inherited disorder characterized by abnormal movements and progressive dementia. Its onset is often delayed until after the

Received for publication 24 June 1983 and in revised form 14 March 1984.

1. Abbreviations used in this paper: HD, Huntington's disease; KPB, potassium phosphate buffer; LMI, leukocyte migration inhibition; MI, migration index; MS, multiple sclerosis.

J. Clin. Invest.

(c) The American Society for Clinical Investigation, Inc. 0021-9738/84/07/0165/08 \$1.00

Volume 74, July 1984, 165-172 affected person has had children, thereby encouraging perpetuation of the gene. Although pathologic changes are well described (1), they represent the end result of cell death, and there are few clues to processes initiating the reaction.

We set out to test the hypothesis that immunologic responses in affected individuals are directed against constituents of brain tissue that become antigenic as a result of the disease process. We used the leukocyte migration inhibition (LMI) technique (2) to detect an immune response to brain tissue. LMI is claimed to be a reliable in vitro index of hypersensitivity $(3,4,5)$, and this is borne out by our own experience with tetanus toxoid as an antigen (6).

A diagnostic test would be of great value in the early stages of HD, when diagnosis is often difficult, particularly if a family history is not available. Furthermore, if the reaction were shown to precede the onset of symptoms, it could prove useful in predicting which children at risk would subsequently develop the disease.

\section{Methods}

Patients and controls. 27 patients ranging in age from 22 to $69 \mathrm{yr}$ (mean of $52 \mathrm{yr}$ ) were studied. In all cases the diagnosis was established by experienced neurologists. Confidentiality of results was guaranteed. $\mathrm{Pa}$ tients had had manifestations of disease for from 1 to $30 \mathrm{yr}$, with a mean of $8 \mathrm{yr}$. 21 were receiving tetrabenazine, thiopropazate, benzodiazepines, and/or phenothiazines. 24 normal healthy controls were tested. Most were laboratory or medical personnel. Their ages ranged from 22 to 83 , with a mean of $34.5 \mathrm{yr}$. 40 patients with other neurologic disorders were also studied. 11 had cerebrovascular disease, 9 had multiple sclerosis (MS), 9 had Alzheimer's disease, 9 had Parkinson's disease, one had a frontal lobe tumor, and one had tardive dyskinesia induced by phenothiazines in treating chronic schizophrenia.

21 normal children of parents with HD were studied, their ages ranging from 15 to $40 \mathrm{yr}$, with a mean of $27 \mathrm{yr}$. Six spouses of HD patients were also tested. Their ages ranged from 45 to $64 \mathrm{yr}$, with mean of $54.5 \mathrm{yr}$.

LMI. LMI was performed after the method of Soborg and Bendixen (2). $40 \mathrm{ml}$ heparinized venous blood was mixed with $5 \mathrm{ml} 5 \%$ dextran $(250,000 \mathrm{~mol} \mathrm{wt})$ in $0.15 \mathrm{M}$ saline and was allowed to separate at $37^{\circ} \mathrm{C}$ for $45 \mathrm{~min}$. Leukocytes in the supernatant were washed three times and resuspended in M199 medium (Gibco Laboratories, Grand Island, NY), 
and cell concentrations were adjusted to between 0.1 and $0.3 \times 10^{8}$, $\mathrm{ml}$. Cells were packed in sealed capillary tubes (Clay Adams, Div. Becton, Dickinson and Co., Parsippany, NJ) by centrifugation at $250 \mathrm{~g}$ for 10 $\mathrm{min}$. Tubes were cut at the cell fluid interface and placed in chambers in leukocyte migration plates (Sterilin; Middlesex General Industries, Inc., Woburn, MA) in medium containing 10\% horse serum (Flow Laboratories, Inc., McLean, VA), penicillin, and streptomycin, with or without antigen. Details of brain preparations used as antigen are given below. In some experiments, rat kidney, liver and heart, and bovine serum albumin (Fraction V; Armour Pharmaceutical Co., Tarrytown, $\mathrm{NY}$ ) were tested at the same time as rat brain.

After $16 \mathrm{~h}$ of incubation at $37^{\circ} \mathrm{C}$, cell migrations were projected and their areas were measured by planimetry. Experiments were conducted blind, without knowledge of the source of cells. One or more control subjects were included in each experiment. At least six migration areas were obtained for each variable. The migration index (MI) was the ratio of the area of migration with antigen to the area of migration without antigen. MI for the normal controls ranged from 0.71 to 1.16 , with a mean \pm 1 SD of $0.96 \pm 0.09$. From our observations on normal controls, we have taken values for MI of $<0.79$ to be indicative of hypersensitivity (i.e., mean -2 SD for $n=56$ ). Reproducibility of the assay was determined by repeating the study from two to nine times on six controls and eight patients on separate samples and on different days. The mean coefficient of variation in migration areas for each variable was 7.7. There was no significant difference between mean MI values of 21 normal controls and nine repeated assays on the same subject.

Preparation of brain antigen. All procedures that involved preparations of brain antigen, including column chromatography, were undertaken at $4^{\circ} \mathrm{C}$. Brains from anesthetized adult Wistar rats were homogenized for $3 \mathrm{~min}$ in phosphate buffered saline (PBS), pH 7.3, and the suspension was adjusted to a final concentration of $100 \mathrm{~g} /$ liter. Suspensions were centrifuged at $27,000 \mathrm{~g}$ for $40 \mathrm{~min}$. Supernatants were used immediately or stored in $1-\mathrm{ml}$ aliquots at $-70^{\circ} \mathrm{C}$ and used within $1 \mathrm{mo}$. There was no difference in MI values obtained with fresh preparations or with those stored as indicated. Fresh calf, human, and rabbit brain were subjected to the same procedure. Human brain was obtained at autopsy within $16 \mathrm{~h}$ of death from patients with no evidence of neurologic disease.

Purification and characterization of brain antigen. Crystalline ammonium sulfate was added slowly to brain antigen to $40 \%$ saturation. It was centrifuged at $27,000 \mathrm{~g}$ for $40 \mathrm{~min}$. The precipitate was resuspended in $\sim 10 \mathrm{ml} 25 \mathrm{mM}$ potassium phosphate buffer (KPB), pH 7.8. This was designated the $\mathrm{P} 40$ fraction. More ammonium sulfate was added to the supernatant of the $\mathrm{P} 40$ fraction to give a $60 \%$ saturated solution. The resulting precipitate was prepared as above (P60 fraction). Ammonium sulfate was added to the supernatant of the P60 fraction to $95 \%$ saturation. The precipitate was resuspended and treated as above (P95 fraction). Fractions were dialyzed against three changes of $25 \mathrm{mM}$ KPB for $24 \mathrm{~h}$. Protein determinations were performed on all fractions by the method of Lowry using bovine serum albumin as the standard (7). Fractions were stored at $-70^{\circ} \mathrm{C}$ for up to $1 \mathrm{mo}$.

Approximately $100 \mathrm{mg}$ P40 fraction in $20 \mathrm{ml} \mathrm{KPB}$ was applied to DEAE Sephacel anion exchange columns $(K 26 \times 40 \mathrm{~cm}$; Pharmacia Fine Chemicals, Uppsala). Bound protein was eluted with a linear sodium chloride gradient. Peak fractions were concentrated (Diaflo YM10 membranes; Amicon Corp., Scientific Systems Div., Danvers, MA) and dialyzed against PBS, pH 7.3, for $24 \mathrm{~h}$. They were stored in the same way as the ammonium sulfate precipitated fractions were. Absorbance of eluants was monitored at $254 \mathrm{~nm}$.

To obtain preliminary information on properties of the material eliciting hypersensitivity, $\mathrm{P} 40$ was divided into five fractions which were treated as follows: no treatment (control); heated at $100^{\circ} \mathrm{C}$ for $5 \mathrm{~min}$; heated at $56^{\circ} \mathrm{C}$ for $30 \mathrm{~min}$; or incubated at $4^{\circ} \mathrm{C}$ with an equal volume of $15 \%$ trichloracetic acid (TCA). Precipitates were centrifuged at 250 $g$ for $10 \mathrm{~min}$ and the supernatants were collected. A further fraction was shaken with chloroform-ether (equal parts) in a ratio of $1: 2$ for 5 min at $4^{\circ} \mathrm{C}$ and allowed to separate over $16 \mathrm{~h}$, and the aqueous phase was collected. All fractions were dialyzed against PBS, pH 7.3, for 24 $h$ and tested for activity in LMI. The sugar content of brain antigen eluted from ion exchange chromatography was determined by the phenol sulfuric acid reaction (8).

Statistics. Comparison of means between experimental and control groups was made by the standard $t$ test for uncorrelated groups.
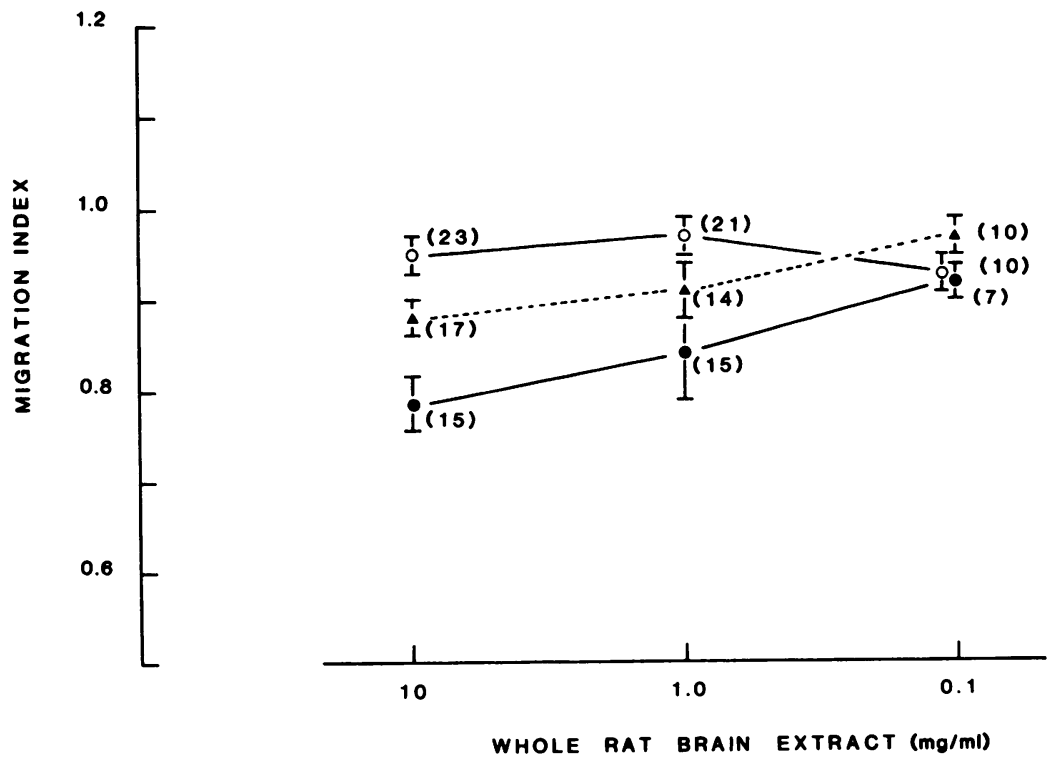

Figure 1. LMI to supernatant of homogenized rat brain in patients with HD (๑), normal controls (0), and in patients with other neurologic diseases $(\boldsymbol{\Lambda})$. Points represent mean \pm 1 SEM. Numbers of observations are shown in parentheses. 
Table I. LMI with Preparations of Rat Tissues and Bovine Serum Albumin in Patients with HD and in Normal Controls

\begin{tabular}{|c|c|c|c|c|c|c|c|c|}
\hline & \multicolumn{8}{|c|}{$\operatorname{MI}(\text { mean } \pm l S D)^{*}$} \\
\hline & \multicolumn{3}{|c|}{ Supernatants of rat tissue $(10 \mathrm{mg} / \mathrm{ml})$} & \multicolumn{4}{|c|}{ Ammonium sulfate precipitated rat tissue (P40) $(50 \mu \mathrm{g} / \mathrm{ml})$} & \multirow{2}{*}{$\begin{array}{l}\text { Bovine serum } \\
\text { albumin } \\
(50 \mu \mathrm{g} / \mathrm{ml})\end{array}$} \\
\hline & Brain & Liver & Kidney & Brain & Liver & Kidney & Heart & \\
\hline \multicolumn{9}{|l|}{$\begin{array}{c}\text { Huntington's } \\
\text { disease }\end{array}$} \\
\hline$(n=6)$ & $0.72 \pm 0.04$ & $1.02 \pm 0.15$ & $0.95 \pm 0.07$ & $0.78 \pm 0.09$ & $0.95 \pm 0.08$ & $0.95 \pm 0.11$ & $0.91 \pm 0.08$ & $0.99 \pm 0.11$ \\
\hline $\mathrm{P} \ddagger$ & - & $<0.005$ & $<0.001$ & - & $<0.02$ & $<0.02$ & $<0.05$ & $<0.01$ \\
\hline \multicolumn{9}{|l|}{ Controls } \\
\hline$(n=3)$ & $0.99 \pm 0.09$ & $0.97 \pm 0.18$ & $0.99 \pm 0.11$ & $1.17 \pm 0.12$ & $1.04 \pm 0.14$ & $1.06 \pm 0.02$ & $1.07 \pm 0.13$ & $1.09 \pm 0.08$ \\
\hline $\mathrm{P} \ddagger$ & - & NS & NS & - & NS & NS & NS & NS \\
\hline $\mathrm{P} \S$ & $<0.005$ & NS & NS & $<0.001$ & NS & NS & NS & NS \\
\hline
\end{tabular}

$\mathrm{NS}$, not significant. ${ }^{*} \mathrm{MI}=($ Area of migration with antigen)/(area of migration without antigen $)$ in LMI assay. MI $<0.79$ indicates hypersensitivity (values in italics). ¥ Comparison of MI for brain with those of other tissues and bovine serum albumin. § Comparison of MI for HD patients and normal controls.

\section{Results}

Migration areas in the absence of antigen were similar in HD

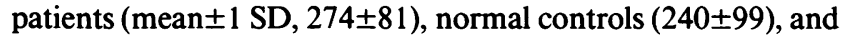

controls with other neurologic diseases (259 \pm 79 ), with $P>0.05$ and $>0.40$ when HD patients were compared with each of the control groups, respectively.

Hypersensitivity to supernatant of rat brain homogenate. 15

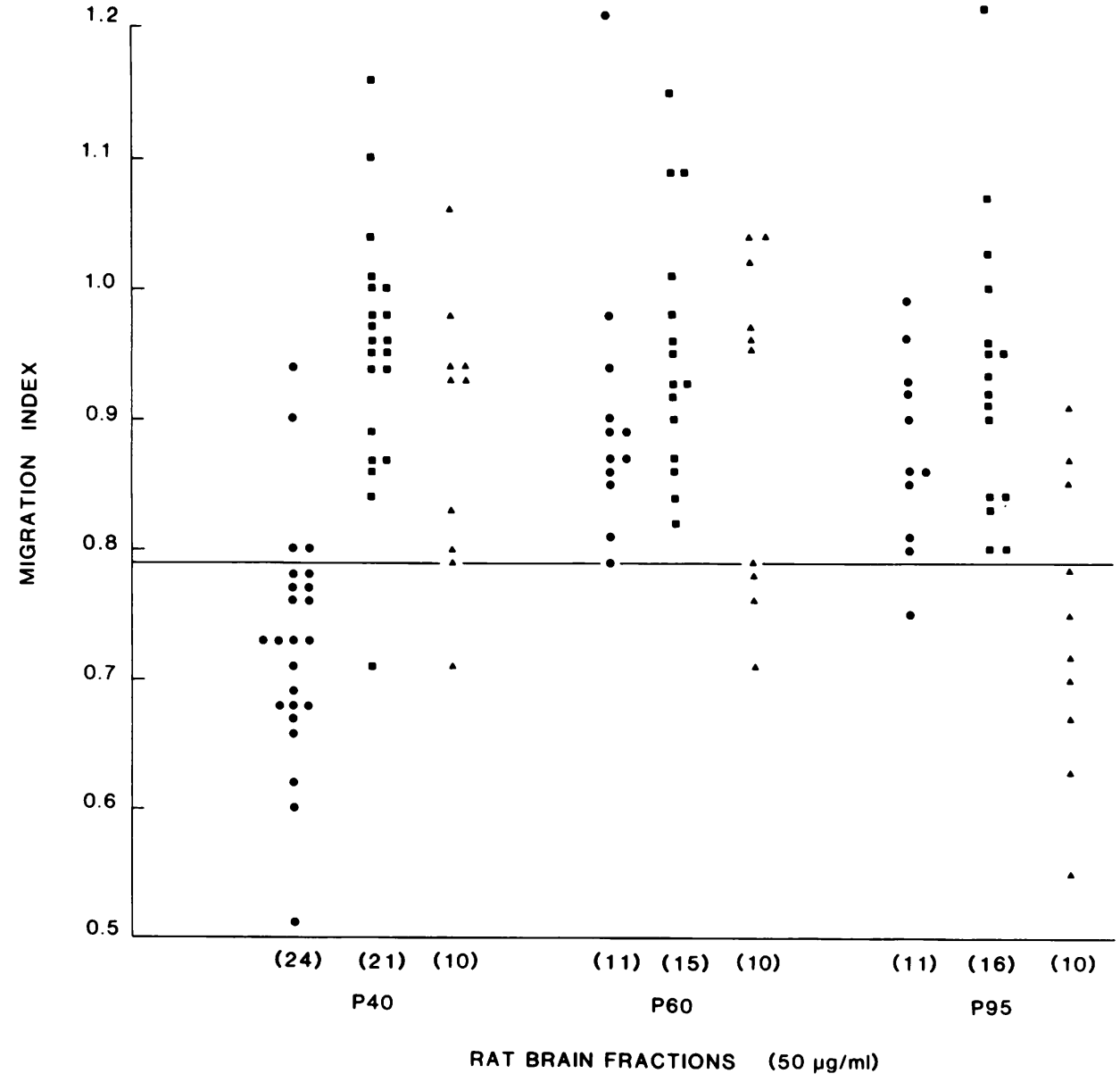

Figure 2. LMI to fractions of rat brain precipitated by $40 \%, 60 \%$, and 95\% saturated ammonium sulfate. Horizontal line at MI 0.79 represents mean -2 SD of 56 observations in normal controls and is taken as the limit of normal range. Numbers of subjects are shown in brackets. HD patients (๑); normal controls (ם); and patients with recent cerebrovascular accidents $(\mathbf{\Lambda})$. 
patients with established HD, 23 normal controls, and 17 patients with other neurologic diseases were tested with supernatant of rat brain homogenate (Fig. 1). There was significant inhibition of migration in the presence of brain antigen in HD patients compared with normal controls at 10 and $1 \mathrm{mg} / \mathrm{ml}(P<0.001$ and $<0.01$, respectively) and with other neurologic disease controls at $10 \mathrm{mg} / \mathrm{ml}(P<0.05)$. Five HD individuals showed no inhibition of migration. Patients with other neurologic conditions, which included 10 cerebrovascular accidents, 5 cases of Parkinson's disease, one of Alzheimer's disease, and one of frontal lobe tumor showed migration inhibition at $10 \mathrm{mg} / \mathrm{ml}$ antigen concentration only ( $P<0.05$ compared with controls). Preparations of other rat tissues and bovine serum albumin produced no migration inhibition in HD patients or normal controls (Table I).

Hypersensitivity to ammonium sulfate precipitated rat brain preparations. Rat brain extracts precipitated with different concentrations of ammonium sulfate were tested in additional groups of patients with HD or other neurologic disorders and in normal controls (Fig. 2). 20 of 24 HD patients responded to P40 fraction of rat brain, including the 5 who failed to react to whole brain extract. MI (mean \pm 1 SEM) with P40 was $0.74 \pm 0.02$, compared with $0.97 \pm 0.03$ in normal controls and $0.91 \pm 0.03$ in patients with other neurologic diseases $(P<0.001$, comparing HD patients with each of the other groups). 11 HD patients were tested with P60 and P95 fractions. MI (mean \pm 1 SEM) were, respectively, $0.91 \pm 0.04$ and $0.88 \pm 0.02$. The material responsible for migration inhibition in HD was, therefore, precipitated by $40 \%$ ammonium sulfate (P40 fraction).

LMI was performed in 36 patients with other neurologic diseases by the use of rat brain extracts precipitated with different concentrations of ammonium sulfate as an antigen. Seven of 10 patients with cerebrovascular accidents (Fig. 2) reacted to P95 $(P<0.02$ compared with HD patients and $P<0.005$ with normal controls). Mean responses of patients with MS, Parkinson's, and Alzheimer's diseases did not differ from normal controls (Table II). However, one MS patient showed stimulation of migration, and one showed inhibition at the higher antigen concentration to all three ammonium sulfate precipitated fractions. Three patients with Parkinson's disease, one of whom had suffered a stroke 5 wk earlier, and two patients with Alzheimer's disease reacted to P95.

MI (mean \pm 1 SEM) with P40 antigen for HD patients on medications was $0.73 \pm 0.02$, compared with $0.77 \pm 0.02$ for five patients who were receiving no drugs $(P>0.30) .10$ patients with other neurologic diseases were receiving phenothiazines and/or L-dopa at the time of testing. Their MI (mean \pm 1 SEM) did not differ from those of controls who were not receiving drugs (0.96 \pm 0.04 and $0.96 \pm 0.03$, respectively).

Altogether, 27 patients with HD were tested with various

Table II. LMI with Rat Brain Preparations Precipitated by 40\%, 60\%, and 95\% Ammonium Sulphate (P40, P60, and P95) in Patients with HD or with Other Neurologic Diseases, and in Normal Controls

\begin{tabular}{|c|c|c|c|c|c|c|c|}
\hline & \multirow{3}{*}{$\begin{array}{l}\text { No. of } \\
\text { subjects }\end{array}$} & \multicolumn{6}{|c|}{ MI $($ mean $\pm I S D)$ for rat brain preparations $(\mu g / m l)$} \\
\hline & & \multicolumn{2}{|l|}{ P40 } & \multicolumn{2}{|l|}{ P60 } & \multicolumn{2}{|l|}{ P95 } \\
\hline & & 50 & 200 & 50 & 200 & 50 & 200 \\
\hline $\begin{array}{l}\text { Huntington's } \\
\text { disease }\end{array}$ & 24 & $0.74 \pm 0.10^{*}(30) \ddagger$ & $0.74 \pm 0.04 *(7)$ & $0.91 \pm 0.11(11)$ & $0.88(1)$ & $0.88 \pm 0.07(11)$ & $1.12(1)$ \\
\hline $\begin{array}{l}\text { Multiple } \\
\text { sclerosis }\end{array}$ & 9 & $1.01 \pm 0.14$ & $0.98 \pm 0.17$ & $0.96 \pm 0.11$ & $1.00 \pm 0.17$ & $1.01 \pm 0.15$ & $0.91 \pm 0.16(5)$ \\
\hline $\begin{array}{l}\text { Parkinson's } \\
\text { disease }\end{array}$ & 8 & $0.99 \pm 0.09$ & $0.93 \pm 0.14(6)$ & $0.94 \pm 0.13$ & $1.00 \pm 0.12(6)$ & $0.90 \pm 0.17$ & $0.91 \pm 0.17(6)$ \\
\hline $\begin{array}{l}\text { Alzheimer's } \\
\text { disease }\end{array}$ & 8 & $0.97 \pm 0.03$ & $0.94 \pm 0.05$ & $0.97 \pm 0.05$ & $0.94 \pm 0.06$ & $0.98 \pm 0.05$ & $0.88 \pm 0.07$ \\
\hline $\begin{array}{l}\text { Cerebrovascul } \\
\text { accident } \\
\text { (CVA) }\end{array}$ & 9 & $0.89 \pm 0.11$ & - & $0.89 \pm 0.13$ & - & $0.74 \pm 0.11 \S$ & - \\
\hline $\begin{array}{l}\text { Parkinson's } \\
\text { disease plus } \\
\text { CVA }\end{array}$ & 1 & 0.94 & - & 0.96 & - & 0.75 & - \\
\hline $\begin{array}{l}\text { Tardive } \\
\text { dyskinesia }\end{array}$ & 1 & 0.85 & 0.85 & 0.96 & 0.91 & 0.84 & 0.85 \\
\hline $\begin{array}{l}\text { Normal } \\
\text { controls }\end{array}$ & 21 & $0.97 \pm 0.11(38)$ & $0.96 \pm 0.09(9)$ & $0.96 \pm 0.14$ & $0.99 \pm 0.14(6)$ & $0.95 \pm 0.12$ & $0.91 \pm 0.10(6)$ \\
\hline
\end{tabular}

MI values in italics indicate hypersensitivity. $* P<0.001$ compared with normal controls and with other neurologic disease controls. $¥$ Numbers of observations are shown in parentheses when they differ from numbers of subjects tested. $\$ P<0.005$ compared with normal controls, and $P<0.02$ compared with HD. 


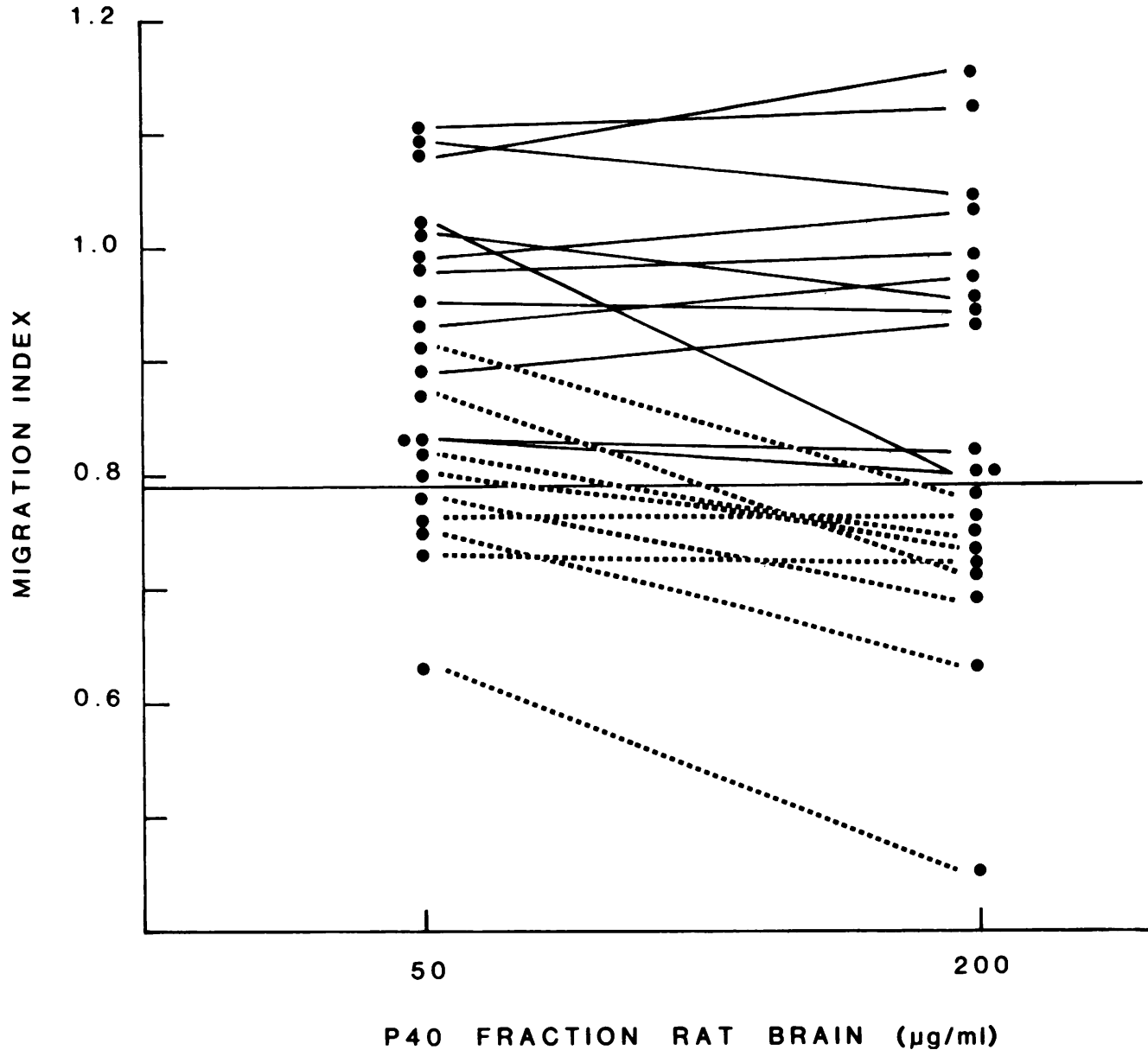

Figure 3. LMI in apparently healthy children of subjects with HD to P40 rat brain fractions. Broken lines indicate subjects considered to show a positive reaction. Horizontal line at MI 0.79 represents lower limit of normal range (see Fig. 2). preparations of brain tissue, and 26 responded to at least one. Those who did not react to the supernatant of brain homogenate or ammonium sulfate precipitated material responded to preparations recovered from gel chromatography. The one patient who failed to respond was not tested with these fractions.

Hypersensitivity to brain antigen in individuals at risk and spouses of $H D$ patients. 21 children of subjects with established HD who showed no clinical evidence of the disease and who were in good health were tested with P40 rat brain fractions at 50 and $200 \mu \mathrm{g} / \mathrm{ml}$. Migration inhibition was demonstrated in nine subjects (Fig. 3), five of whom were positive at both concentrations of antigen, and four who were positive at $200 \mu \mathrm{g} /$ $\mathrm{ml}$ only. In 12 subjects the MI was within normal limits. The mean age of children with positive reactions was $26 \mathrm{yr}$, and of those without hypersensitivity it was $27.6 \mathrm{yr}$.

Six spouses of HD patients were tested with supernatant of rat brain homogenate or with P40 at 50 and $200 \mu \mathrm{g} / \mathrm{ml}$. None showed inhibition of leukocyte migration.

Species specificity of brain tissue antigen. P40 fractions prepared from rat, human, calf, and rabbit brain were used at 50 $\mu \mathrm{g} / \mathrm{ml}$ as the antigen in patients with HD and in controls (Fig. 4). Brain tissue from the four species was equally antigenic in LMI.
Characterization and purification of brain tissue antigen. Supernatants of rat brain P40 fractions that had been heated, precipitated with $15 \%$ TCA, or extracted with chloroform-ether served as antigen at $50 \mu \mathrm{g} / \mathrm{ml}$ in three patients with HD. In comparison with untreated antigen (mean MI \pm 1 SEM, $0.71 \pm 0.02$ ), migration inhibition was abolished by heating the antigen at $100^{\circ} \mathrm{C}$ for $5 \mathrm{~min}(\mathrm{MI} 0.96 \pm 0.05, P<0.02)$ or at $56^{\circ} \mathrm{C}$ for $30 \mathrm{~min}$ (MI $0.92 \pm 0.07, P<0.005$ ), or by precipitating the antigen with $15 \%$ TCA (MI $0.98 \pm 0.06, P<0.02$ ) or with chloroform-ether (MI 0.90 $\pm 0.07, P<0.05$ ).

To purify further the P40 fraction it was applied to anion exchange columns. Similar elution patterns were obtained on each of six occasions. A representative profile is shown in Fig. 5. The eluted fractions were adjusted to a protein concentration of $50 \mu \mathrm{g} / \mathrm{ml}$ for use in LMI. Material eluted at 0.4 and $0.5 \mathrm{M}$ $\mathrm{NaCl}$ inhibited leukocyte migration in HD patients compared with controls, indicating that they contained the antigenic material (Table III). Similar elution profiles were obtained from human and calf material. Material eluted at 0.4 and $0.5 \mathrm{M}$ from human brain was maximally active in LMI (Table III).

The sugar content of five brain fractions eluted at $0.4 \mathrm{M}$ from anion exchange chromatography was $39 \pm 10 \mu \mathrm{g} / \mathrm{ml}$ (mean $\pm 1 \mathrm{SD}$ ), with a protein/sugar ratio of 28:1. 


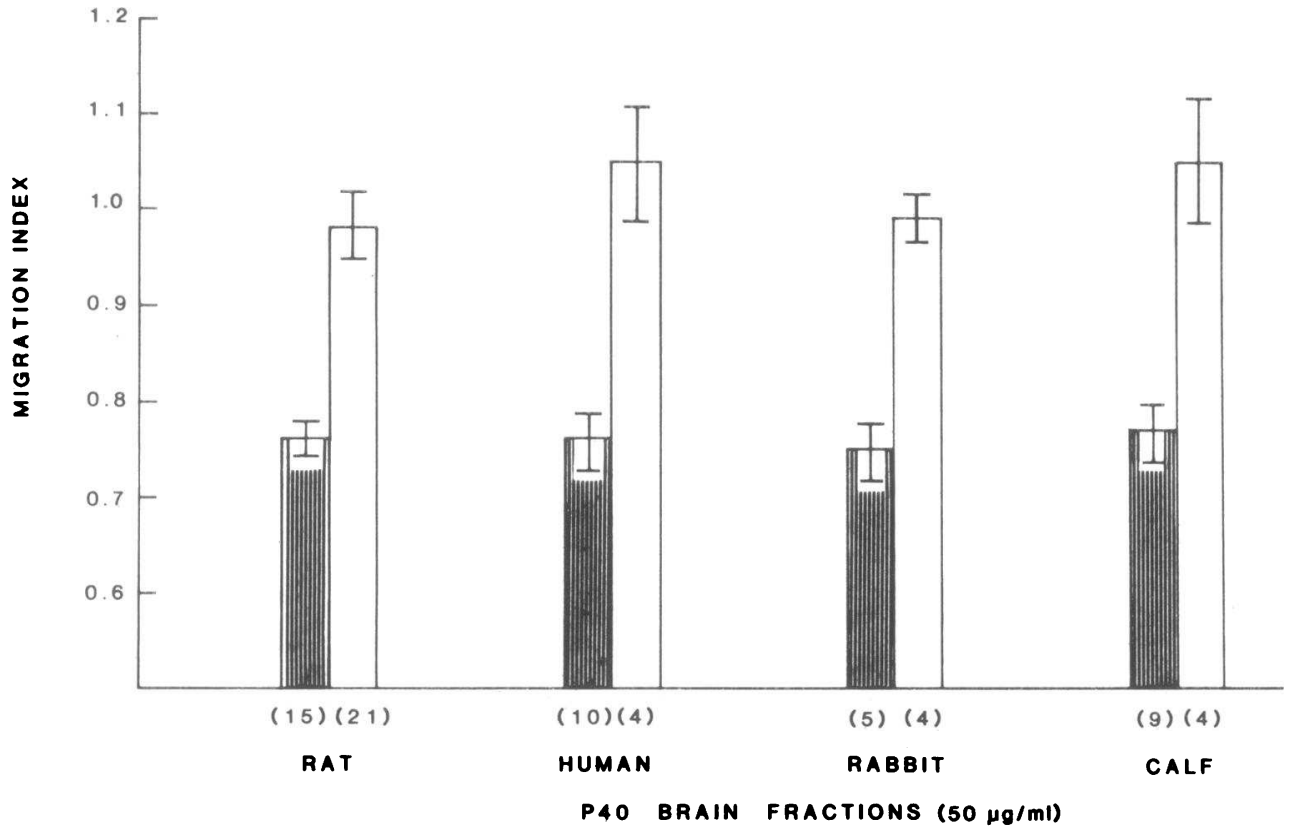

Figure 4. LMI to P40 brain fractions prepared from different species in subjects with HD (shaded bars) and normal controls (open bars). Bars represent mean \pm 1 SEM. Numbers of subjects are shown in brackets.

\section{Discussion}

We have shown that patients with established HD and a proportion of individuals at risk respond to brain tissue extracts in the LMI test. The phenomenon is reproducible and dose dependent. Only HD subjects and individuals at risk react substantially to brain tissue material, and the reaction does not occur in patients with other neurologic diseases. Migration is inhibited only by particular brain fractions and not by other rat tissues tested or by bovine serum albumin. To this extent, it represents a specific reaction to some constituent of brain in
HD patients and individuals at risk. Whatever the mechanisms for LMI $(5,9)$, be they the interaction of antigen with lymphocytes to generate lymphokines or with cytophilic antibodies on the surface of target cells, LMI is accepted as an in vitro correlate of delayed hypersensitivity in man $(3,4,5,9)$. Direct cytotoxicity of antigen is excluded in our experiments by its lack of effect on cells from various controls. Further, we have found in our laboratory that LMI with tetanus toxoid correlates well with delayed hypersensitivity skin testing (6). We suggest, therefore, that the phenomenon indicates an immunologic response. The relevant antigen is present in normal brain of several

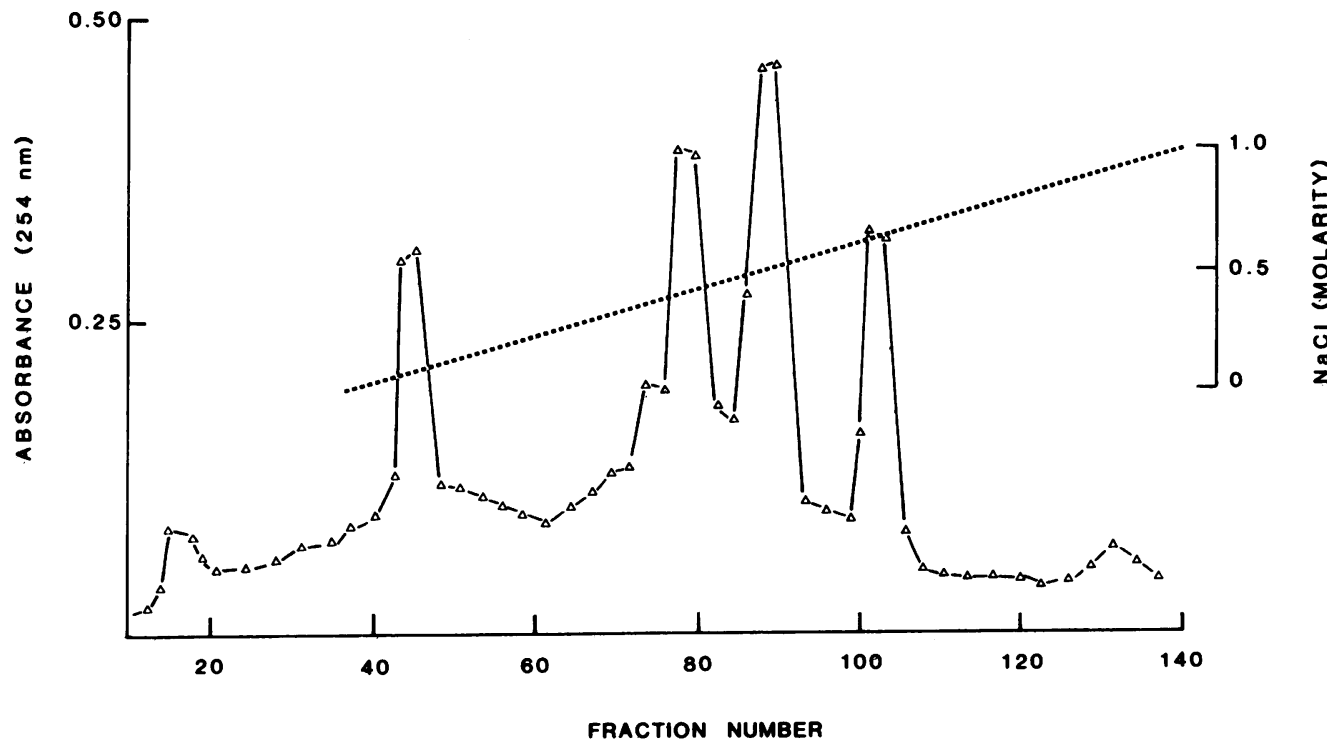

Figure 5. Elution profile of P40 rat brain from anion exchange chromatography. Increasing concentration of $\mathrm{NaCl}$ is shown as a broken line. 
Table III. LMI in HD Patients and Normal Controls, with Fractions Eluted from Anion Exchange Chromatography

\begin{tabular}{|c|c|c|c|c|c|c|c|c|}
\hline & \multicolumn{8}{|c|}{ MI of fractions eluted (mean $\pm I S D$ ) } \\
\hline & Pregradient & Pregradient & $0.18 \mathrm{M}$ & $0.31 \mathrm{M}$ & $0.40 \mathrm{M}$ & $0.50 \mathrm{M}$ & $0.68 \mathrm{M}$ & $0.90 \mathrm{M}$ \\
\hline \multicolumn{9}{|l|}{ Rat brain } \\
\hline Patients & $0.90 \pm 0.03(3)$ & $1.00 \pm 0.18(3)$ & $0.94 \pm 0.11(3)$ & $0.94 \pm 0.13(4)$ & $0.78 \pm 0.08(4)$ & $0.63 \pm 0.14(4)$ & $0.81 \pm 0.10(4)$ & $1.05 \pm 0.10$ \\
\hline Controls & $0.96 \pm 0.06(2)$ & $0.93 \pm 0.04(2)$ & $1.00 \pm 0.02(2)$ & $0.95 \pm 0.13(3)$ & $1.00 \pm 0.06(3)$ & $0.91 \pm 0.12(3)$ & $0.78 \pm 0.05(2)$ & $0.94 \pm 0.12(2)$ \\
\hline \multirow[t]{2}{*}{$P$} & NS & NS & NS & NS & $<0.001$ & $<0.05$ & NS & NS \\
\hline & Pregradient & & $0.20 \mathrm{M}$ & & $0.40 \mathrm{M}$ & $0.50 \mathrm{M}$ & $0.68 \mathrm{M}$ & \\
\hline \multicolumn{9}{|c|}{ Human brain } \\
\hline Patients & $0.84 \pm 0.10(5)$ & & $0.82 \pm 0.05(5)$ & & $0.71 \pm 0.10(7)$ & $0.72 \pm 0.05(7)$ & $0.87 \pm 0.10(6)$ & \\
\hline Controls & $0.90 \pm 0.16(5)$ & & $0.90 \pm 0.13(5)$ & & $1.11 \pm 0.20(4)$ & $1.07 \pm 0.09(4)$ & $0.97 \pm 0.06(4)$ & \\
\hline$P$ & NS & & NS & & $<0.005$ & $<0.001$ & NS & \\
\hline
\end{tabular}

MI values in italics indicate hypersensitivity. Significance limits refer to comparisons between patients and controls. NS, not significant. Number of subjects tested is shown in parentheses.

species. It is heat labile, contains sugars, is extractable with lipid solvent, and is precipitated by TCA, indicating that it is probably composed of protein.

There are several possible explanations for the immune response in HD. First, the antigen may be made accessible to immunocompetent cells by the primary pathologic process. Second, the defective gene, a transmissible agent, or both may alter the molecular structure of a normal brain constituent, thereby rendering it antigenic. The recent discovery of a genetic marker for HD by Gusella et al. (10) allows this question to be addressed, and further characterization may identify the antigen as the abnormal gene product. Dominantly inherited disorders are characterized by alterations in structural proteins (11) such as cell membranes, which have been examined in $\operatorname{HD}(12,13,14)$ but with inconclusive results (15). It is unlikely that the reaction in $\mathrm{HD}$ is a nonspecific response to injury. We were able to distinguish, by their precipitation with ammonium sulfate, the antigens responsible for migration inhibition in HD from those to which some patients with other neurologic conditions reacted. One such protein released from the brain after injury and designated $\mathrm{S}-100$ is precipitated by $100 \%$ saturated ammonium sulfate (16). The antigen responsible for hypersensitivity in our study differs from those described in other reports in terms of its greater specificity for $\operatorname{HD}(17,18)$, its precipitation with ammonium sulfate (18), and other properties (19).

Barkley et al. (20) reported significantly greater migration inhibition when HD lymphocytes were cultured with HD or MS brain than with normal human brain. They suggested that the major component of the immune response was directed against a transmissible or environmental agent common to HD and MS, such as a virus, with a minor component of the antigen common to all human brain. Unlike Husby et al. (17), whose finding of neuronal antibodies in spouses and first degree relatives of HD patients supports this notion, we were unable to demonstrate hypersensitivity in the few spouses we tested.

Detection of hypersensitivity to brain antigens in normal children of affected parents indicates that it probably precedes the first clinical signs of disease. It may therefore contribute to the pathologic lesions in HD, although evidence for immunologic activity is lacking in ultrastructural studies of HD brains (1). Even if hypersensitivity is only an epiphenomenon, it may prove to be a valuable marker for the diseases, particularly in situations where family histories are lacking. We found LMI to be reproducible, provided that meticulous attention was paid to $\mathrm{pH}$ and the use of fresh material. Despite the relatively small numbers tested, our findings are encouraging with respect to sensitivity, and this could be improved by using purified antigen, as we showed with three patients who reacted not to P40, but to antigen eluted from ion exchange chromatography. Specificity of the test for HD is also promising in that the antigens causing migration inhibition in HD and other neurologic diseases can be distinguished by ammonium sulfate precipitation.

Hypersensitivity in children of HD patients in a ratio approaching that expected in autosomal dominant inheritance raises the possibility that a positive test could predict the onset of HD later in life. A prolonged follow-up will be required before this can be relied upon, but such studies could be shortened by concentrating on families with an early onset of disease.

\section{Acknowledgments}

We wish to thank Physicians and Psychiatrists for permission to study their patients, and the Australian Huntington's Disease Association, at risk individuals, and relatives for their cooperation. We thank Ms. Lynette Hurst and Pauliene Harrop for technical assistance. We are grateful to Dr. David Nelson and Mr. David Tomlinson for helpful discussions and for criticizing the manuscript.

This work was supported by the Department of Veterans' Affairs and by the Postgraduate Committee in Medicine of the University of Sydney.

\section{References}

1. Bruyn, G. W., G. T. M. Bots, and R. Dom. 1979. Huntington's chorea: current neuropathological status. In Advances in Neurology: 
Huntington's Disease. T. N. Chase, N. S. Wexler, and A. Barbeau, editors. Raven Press, New York. 23:83-93.

2. Sorborg, M., and G. Bendixen. 1967. Human lymphocyte migration as a parameter of hypersensitivity. Acta Med. Scand. 181:247256.

3. Rosenberg, S. A., and J. R. David. 1970. Inhibition of leukocyte migration: an evaluation of this in vitro assay of delayed hypersensitivity in man to a soluble antigen. J. Immunal. 105:1447-1452.

4. Mitchell, G., M. G. M. Smith, P. L. Golding, A. L. W. F. Eddleston, and R. Williams. 1972. Evaluation of the leucocyte migration test as a measure of delayed hypersensitivity in man. Clin. Exp. Immunol. 11:535541.

5. Hamblin, A. S., and R. N. Maini. 1980. An evaluation of lymphokine measurement in man. In Recent Advances in Clinical Immunology. R. A. Thompson, editor. Churchill Livingstone Inc., New York. 2:243-273.

6. Johnson, C., R. S. Walls, and A. Ruwoldt. 1983. Delayed hypersensitivity to tetanus toxoid in man: in vivo and in vitro studies Pathology. 15:369-372.

7. Lowry, O. H., N. J. Rosebrough, A. L. Farr, and R. J. Randall. 1951. Protein measurement with the Folin phenol reagent. J. Biol. Chem. 193:265-275.

8. Dubois, M., K. A. Gilles, J. K. Hamilton, P. A. Rebers, and F. Smith. 1956. Colorimetric method for determination of sugars and related substances. Anal. Chem. 28:350-356.

9. Rocklin, R. E. 1981. Properties and mechanism of action of human leucocyte migration inhibitory factor (LIF). In Lymphokines. E. Pick, editor. Academic Press Inc., New York. 2:163-177.

10. Gusella, J. F., N. S. Wexler, P. M. Conneally, S. L. Naylor, M. A. Anderson, R. E. Tanzi, P. C. Watkins, K. Ottina, M. R. Wallace, A. Y. Sakaguchi, A. B. Young, I. Shoulson, E. Bonilla, and J. B. Martin. 1983. A polymorphic DNA marker genetically linked to Huntington's disease. Nature (Lond.). 306:234-238.

11. Becker, P. E. 1971. Genetic approaches to the nosology of muscle disease: myotonias and similar diseases. In Birth Defects: Original Article Series. Williams and Wilkins, Baltimore. 7:52-62.

12. Butterfield, D. A., and W. R. Markesbery. 1979. Erythrocyte membrane alterations in Huntington's disease. In Advances in Neurology: Huntington's Disease. T. N. Chase, N. S. Wexler, and A. Barbeau, editors. Raven Press, New York. 23:397-408.

13. Appel, S. H. 1979. Membrane defects in Huntington's disease. In Advances in Neurology: Huntington's Disease. T. N. Chase, N. S. Wexler, and A. Barbeau, editors. Raven Press, New York. 23:387-396.

14. Noronha, A. B. C., R. P. Roose, J. P. Antel, and B. G. W. Arnason. 1979. Concanavalin A-induced lymphocyte capping in Huntington's disease. In Advances in Neurology: Huntington's Disease. T. N. Chase, N. S. Wexler, and A. Barbeau, editors. Raven Press, New York. 23:419-428.

15. Martin, J. B. 1982 . Huntington's disease: genetically programmed cell death in the human central nervous system. Nature (Lond.). 299:205206.

16. Michetti, F., A. Massaro, G. Russo, and G. Rigon. 1980. The S-100 antigen in cerebrospinal fluid as a possible index of cell injury in the nervous system. J. Neurol. Sci. 44:259-263.

17. Husby, G., L. Li, L. E. Davis, E. Wedege, E. Kokmen, and R. C. Williams, Jr. 1977. Antibodies to human caudate nucleus neurons in Huntington's chorea. J. Clin. Invest. 59:922-932.

18. Hardiwidjaja, S. I., A. Morgan, G. W. Ellison, L. W. Myers, W. G. Pierce, and D. S. Barkley. 1981. Huntington's disease and leucocyte adherence inhibition (LAI). Clin. Exp. Immunol. 45:583-589.

19. Husby, G., E. Wedege, and R. C. Williams, Jr. 1978. Characterization of brain proteins reacting in vitro with anti-neuronal antibodies in patients with Huntington's disease. Clin. Immunol. Immunopathol. 11:131-141.

20. Barkley, D. S., S. I. Hardiwidjaja, J. H. Menkes, G. W. Ellison, and L. W. Myers. 1977. Cellular immune responses in Huntington's disease (H.D.). Detection of H.D. and multiple sclerosis (M.S.) brain antigenicity by H.D. but not M.S. lymphocytes. Cell. Immunol. 32:385390. 